\title{
Using Functional Communication Training to Reduce Screaming Behavior in a Young Girl with Autism
}

\author{
Dimitra Chaldi \\ Correspondence to: Dimitra Chaldi, PhD. Student (Faculty of Medicine), M.ADS, BSc. S-LP \\ Speech - Language Pathologist \& Behavior Therapist at "Speech Rehabilitation Institute", \\ Patra, Greece \\ E-mail: dimitrachaldi.speech@gmail.com \\ Phone number: $(+30) 6951712786$ \\ Address: Karpasias 7 \& Archiepiskopou Makariou, 26441, Patra, Greece
}

\begin{abstract}
Children with autism may engage in challenging behaviors due to language delays and lack of functional communicative repertoire. The present case study examines a 5-year old girl with autism who engages in screaming induced by accessibility to tangibles. The primary objective was to assess and identify the function of screaming and propose an effective intervention plan. Initially, a parametric analog assessment was conducted to identify the most effective schedule of reinforcement using the Antecedents-Behavior-Consequences and the Questions About Behavioral Function. The results showed that access to tangibles promote screaming behavior. The Functional Communication Training and daily preference assessment were used to develop her manding, while decreasing the occurrence of screaming. The intervention resulted in a significant increase in the client's requesting for a preferred item across 10 sessions with a concomitant decrease in the occurrence of screaming.
\end{abstract}


Keywords: Autism Spectrum Disorder, Functional Communication Training, Preference Assessment, Screaming.

Note: all names in the paper have been changed

\section{Objective}

Children with developmental disabilities (DD), such as autism spectrum disorder (ASD), often have difficulties with their interactive verbal skills. More specifically, they may have limited mand repertoires, instead engaging in challenging behaviors (e.g., screaming, hitting) to obtain desirable consequences (O’Neil, 1990).

ASD is a neurodevelopmental disorder which can be diagnosed based on the Diagnostic and Statistical Manual of Mental Disorders (DSM-IV-TR). The diagnostic criteria show that these children have deficits in their social interaction, communication impairments, and repetitive and stereotypic behaviors (Johnson \& Myers, 2007). McClintock, Hall, and Oliver (2003), conducted literature review according the risks markers for challenging behaviors. They collected and analyzed 86 articles between 1960 and 2003 and all were based on challenging behaviors and DD. The results of the meta-analysis showed that one of the risk marker for challenging behaviors (screaming, aggression), was the diagnosis of ASD.

Matson et al. (2011) stated that, in ASD, challenging behaviors might occur due to environmental factors (e.g., access to tangibles), cognitive level, and communication deficits. Based on these, the lower the cognitive level, the higher the chances of the child to engage in challenging behavior.

To identify the function of target behaviors to individuals with DD, a functional communication assessment (FBA) should be conducted. An FBA typically includes collection of information using direct (e.g., Antecedent - Behavior-Consequences (A-B-C)), indirect (e.g., interview), and experimental procedures (i.e., functional analysis (FA)) (Cooper, Heron, \& Heward, 2007, pp. 48-71; Kahng, Ingvarsson, Quigg, Seckinger, \& Teichman, 2011).

Galiatsatos and Graff (2003) assessed screaming in a 13-years-old who had been diagnosed with ASD, pervasive disorder, and obsessive compulsive disorder. The authors conducted FA and A-B-C assessments and found that both assessments revealed a tangible function for the behavior. Tarbox et al. (2009), compared different types of assessments of challenging 
behaviors in children with ASD. Participants were seven children between 3-9 years old, diagnosed with ASD who engaged in challenging behaviors (e.g., screaming, kicking) with different functions. To determine the function of these behaviors, the researchers collected frequency data along with using Questions About Behavioral Function (QABF), A-B-C, and FA. There was exact agreement across all measures.

As children with ASD experience delays and deficits in their communication skills, it is important to develop functional communication for them, and that can be achieved through functional communication training (FCT). The FCT teaches communication responses which serve the same function with the challenging behavior (Rutherford, 2012).

Sigafoos and Meikle (1996) used mand training to reduce multiply maintained aggression and self-injurious behaviors (SIB). Using mand training, the experimenters replaced these behaviors with more appropriate mands. Chiang (2008) found that, for 32 non-verbal or minimally verbal children in a school environment, challenging behavior had a tangible function, suggesting that the children used these behaviors to communicate. The author recommended that, by improving expressive language skills, practitioners can develop more functional forms of communication for their clients.

Accompanying FCT with preference assessments may help further reduce challenging behaviors (Canella, O’Reilly, \& Lancioni, 2005). Piazza, Fisher, Hagopian, Bowman, and Toole (1996) demonstrate the effectiveness of using a paired stimulus preference assessment by comparing its results to a reinforcer assessment. The results showed that high-preference items functioned as reinforcers for all 4 clients, middle-preference item functioned as reinforcers for only two clients, and the low-preference items did not function as reinforcers.

\section{Participant}

Eva is a 5-year old girl who was born and raised in Canada from Canadian parents, and has a typically developing adolescent sister. When she was 18 months old, her pediatrician referred her for developmental delay and ASD screening. During the screening, her parents completed the Modified Checklist for Autism in Toddlers-Revised (M-CHAT-R), with positive results. Then, she went through further medical and developmental assessments and was diagnosed with ASD. She lacks a vocal repertoire and engages in challenging behaviors, specifically screaming.

Based on the Verbal Behavior Milestones Assessment and Placement Program (VB-MAPP) (Sundberg, 2008), Eva has strong play, echoic and imitation skills, and she can follow simple 
one-step instructions. The areas that need improvement include requesting, expressive language, and problematic behavior including screaming, flopping, and head-banging (screaming is precursor for the occurrence of the last two behaviors).

\section{Consent process for parents}

\section{Consent for involvement in the project}

Her parents provided written consent on a form outlining the purpose of the project, what it will include, the type of information the investigator will need for the project, how long it will last, and the benefits and risks of her participation. Parents were also informed about how the information will be kept anonymous and that they will be able to withdraw their consent at any time.

\section{Consent for assessment}

A separate consent form for assessment explained all procedures that will be involved using simple language, including the settings, individuals involved, and the assessment-specific risks and benefits. The form also indicated that the investigators will share the assessment results with the parents and use these results to develop an effective intervention for Eva (Bailey \& Burch, 2016, pp.109-122).

\section{Intervention Consent Form}

Before starting the intervention, we informed parents about the assessment results, we explained to them our proposed intervention, and we asked them if they agree with the plan. Once we had their written permission through the intervention consent, we started the intervention. Our behavior analytic consent, explained to parents all the procedures that will be implemented, and how the results will be used.

\section{Operational Definition}

Screaming is defined as any vocalization above conversational volume for at least $2 \mathrm{~s}$ in inappropriate contexts. An instance ends when there are no vocalizations for $5 \mathrm{~s}$. Screaming may be a precursor for crying, hitting, flopping, and/or head-banging. Non-examples include whispering or speaking at a conversational level with whole words or vocal approximations, or screaming in appropriate situations (e.g., during certain games). 
Manding is defined as the verbal behavior which is under the control of the establishing operations (EO). Examples of manding include utterances, made at an appropriate conversational volume, connected to specific item(s) in the environment and with a potential EO for the item(s). Non-examples include non-appropriate verbal approximation of the item, screaming, hitting, and crying to ask for an item.

\section{Biopsychosocial Factors}

\section{Biological Factors}

Eva has been diagnosed with ASD and no any other syndromes/disorders or medical conditions. The only issue her parents have mentioned is sleep problems, which can affect her mood during the day and can increase the occurrence of her target behaviors. Nevertheless, parents stated that they are not collecting sleep data and have not yet consulted with a doctor, but are planning to do that in the immediate future.

\section{Psychological Factors}

Eva's limited vocal and non-verbal communicative repertoire and can increase the occurrence of screaming and result in distress because of difficulty conveying her wants and needs. There is no indication that she has any other relevant factors, such as intellectual disability (ID).

She does not use gestures and does not point, which is another factor which can increase the likelihood of Eva engaging in screaming when she wants to communicate with other people. Lastly, it has not been reported any other issue according her cognitive function, such as mental retardation and social interaction deficits.

\section{Social Factors}

Eva does not have friends and does not engage to any active participation in activities with other children, as her parents are worried about her challenging behavior. They reported that in the past because she did not have access to another child's toy she started screaming and she hit the child.

\section{Social Relevance of the behavior change}

Eva's challenging behavior poses a barrier to her learning, limits her social interaction opportunities, and may lead to restrictive placements in the future (e.g., residential settings) (Koegel, Koegel, Boettcher, Harroer, \& Openden, 2006). Replacing her challenging behavior 
with appropriate communication will increase the likelihood of optimal outcomes, including improvement in her overall quality of life (e.g., by decreasing health problem risks).

\section{Method}

\section{Assessment Plan}

Although most research on FCT included an FA, it was not appropriate for Eva due to safety concerns (i.e., she escalates quickly to flopping and head-banging). So, we used antecedentbehavior-consequence (A-B-C) and Questions About Behavioral Function (QABF) measures to determine the function of screaming. After these assessments, the investigator and the therapist conducted the Parametric Assessment Analog.

Parametric assessment analog. We conducted a parametric analysis of two different schedules of reinforcement to determine the type of fixed ration (FR) schedule of reinforcement that is most effective in reducing rates of screaming and increasing rates of vocal manding.

The parametric analog implemented across six sessions (three days for the FR1 and three days for the FR2). During FR1, the reinforcement was delivered immediately every after correct response, and during FR2, the reinforcement was delivered after every two correct responses.

During the baseline condition, we used non-contingent schedule of reinforcement (NCR), giving Eva access to reinforcement (e.g., IPAD) on a fixed-time 30-s schedule. This dense schedule was selected based on the severity of her challenging behavior and her developmental level. Throughout the manding conditions, reinforcement was provided contingent on Eva's vocal requests, for which the therapist could provide most-to-least prompting. For the FR1 schedule, Eva received her reinforcer (e.g., verbal praise, IPAD, etc.) for every correct response, and during FR2, she received it every two correct responses.

A-B-C/direct observation. Direct observational A-B-C data on every instance of screaming and the environmental conditions where it occurred (e.g., time of the incident, antecedent, and consequent events) were taken using data sheets. The data was collected daily (5 days in total), across Eva's sessions (6 hours), and across all the settings (e.g., her work space, gym, lunch area, washroom).

Questions About Behavioral Function (QABF)/indirect assessment. The QABF (Sundberg, 2008), is a questionnaire consisting of 25 items, with 5 items in each of 5 factors (i.e., 
attention, escape, non-social, physical, and tangible), with behaviors scored based on their occurrence and severity (Matson \& Vollmer, 1995). This assessment was completed and scored in $20 \mathrm{~min}$ by both senior therapist (ST) and Eva's mother, to allow for inter-observer agreement.

\section{Measurement Plan}

For the measurement system, we measured the frequency and the duration of screaming behavior across five sessions (6 hours each one).

Frequency. For screaming, we collected frequency data using tally counters and a timer. Initially, we used extra data sheets, but switched to recording using the A-B-C data sheet and then graphed the data.

Duration. To record duration, we used a digital stopwatch, and data collection forms.

\section{Interobserver Agreement (IOA)}

Two therapists who were working with Eva observed the therapist and collected data for the parametric analog, the A-B-C assessment, and the frequency and duration of screaming at the same time as the therapist across five consecutive sessions. The author calculated the IOA by dividing the smaller of the counts by the larger count, and multiplying by 100 (Cooper, et al., 2007, pp.102-124).

In Figure 1, during baseline, where Eva has free access to tangibles (NCR with FI 30 seconds' times per hour), she did not provide a high number of responses. The data path is quite low, almost close to zero levels, whereas during the FR1, where she received her reinforcement after her every correct response, the number of manding responses increased to almost 18 correct responses per hour. Comparing FR1 with FR2, Eva provided more correct responses per hour during the FR1 where she received reinforcement after every correct response compared to every two correct responses. 

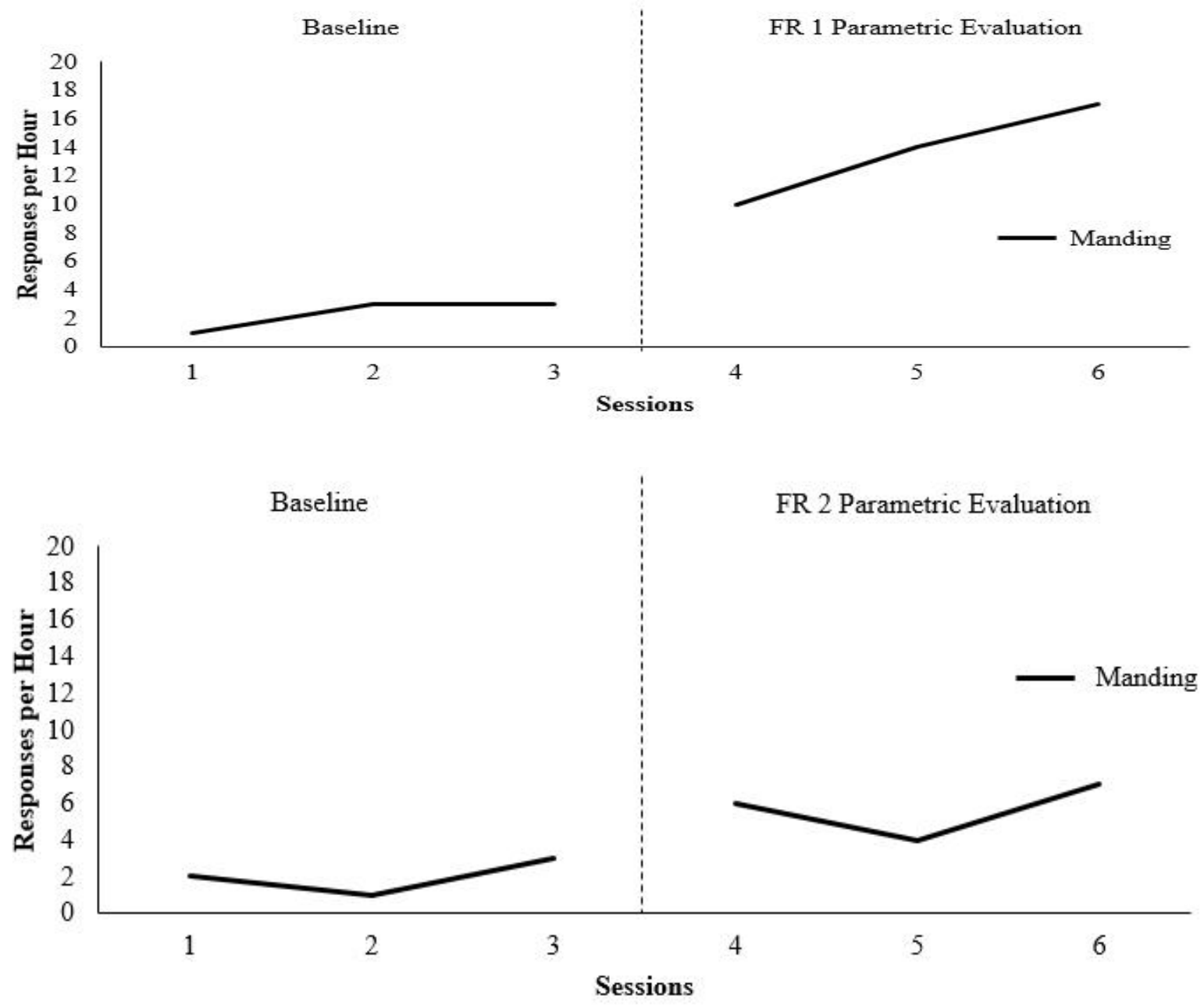

Figure 1. Manding of correct responses to manding task, per hour, across baseline and schedules of reinforcement. The first graph presents data across three days of baseline and three days of FR1.

The second graph presents data across three days of baseline and three days of FR2.

In Figure 2, during baseline, she engaged in screaming (7 times per hour, maximum) whereas during the FR1, the number of times she engaged in screaming behavior reduced to almost zero levels. For the second graph, Eva engaged on screaming behavior few times ( 7 times per hour, maximum). However, during FR2, Eva's screaming increased to almost 10 times per hour). Comparing FR1 with FR2, Eva engaged to less times of screaming behavior per hour during the FR1. Therefore, she engaged in more manding and less screaming per hour when she received reinforcement on an FR1 schedule. 

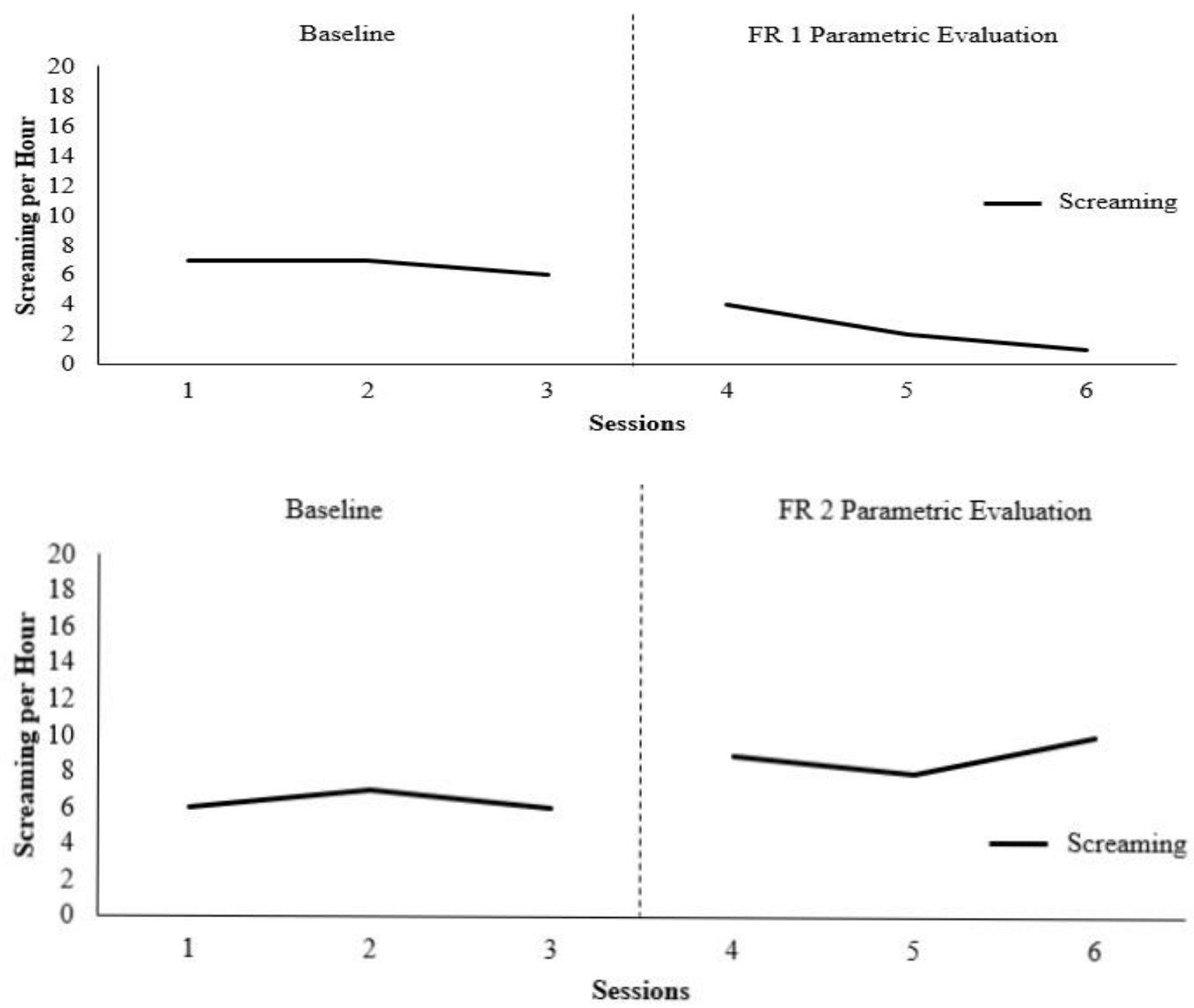

Figure 2. Number of times screaming behavior occurred per hour, during the baseline and during the parametric evaluation FR1 and FR2.

\section{A-B-C/Direct Observation}

The analysis of the A-B-C data (Appendix E) showed that Eva's screaming mostly occurred when she wanted to have access to tangibles. More specifically, the target behavior occurred because she could not have access to another peer's toys and when she wanted to have access to her preferred items.

\section{Questions About Behavioral Function (QABF)/Indirect Assessment}

Both QABFs identified that the function of Eva's screaming was tangible reinforcement, with total scores of 15 from the senior therapist and 14 from mother (Figure 3). 

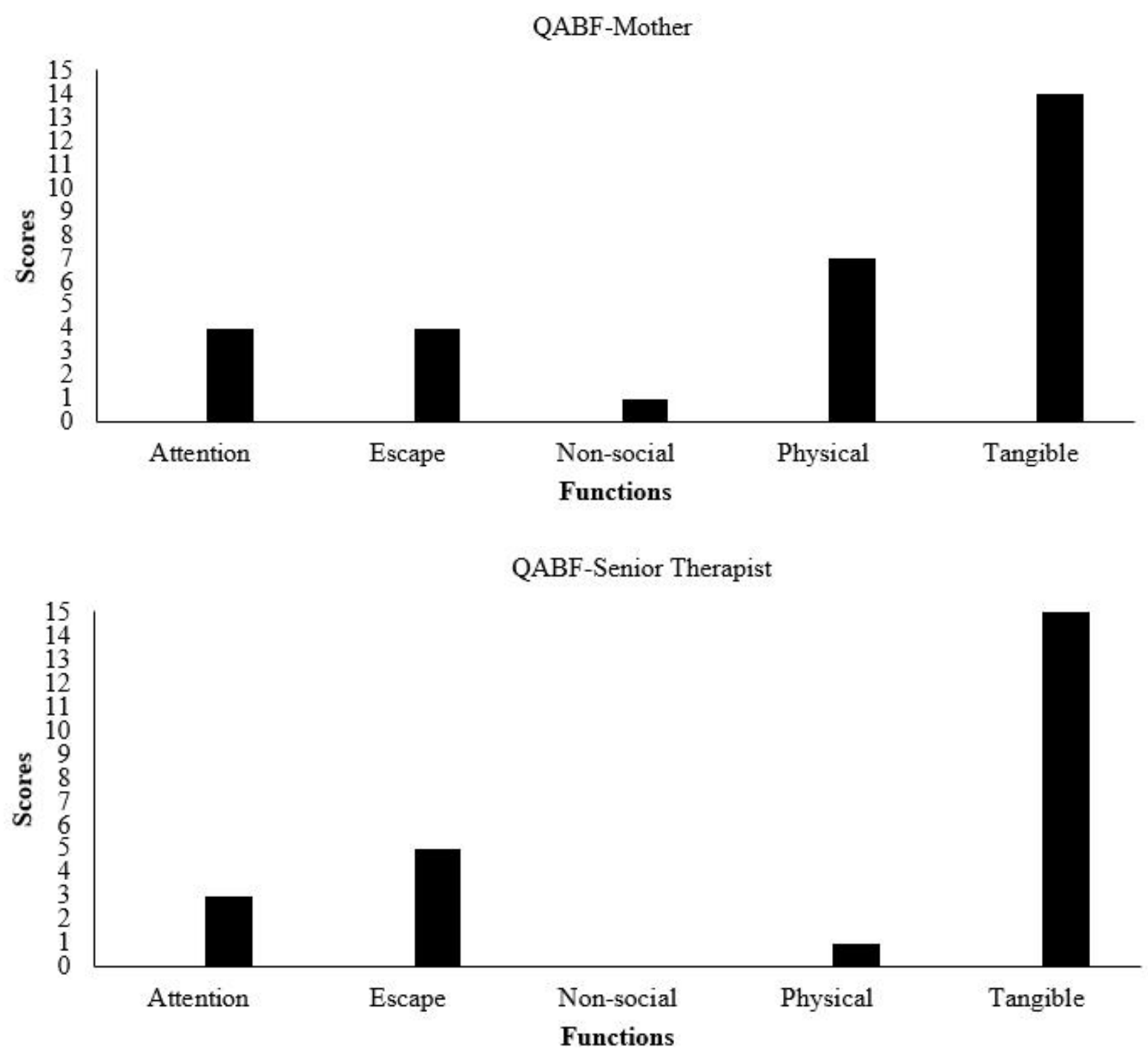

Figure 3. QABF severity scores for Eva presented as bars.

\section{Frequency}

Eva exhibited screaming of moderate frequency during the first two sessions. In the third session, there was a strong increase in frequency, which then fell back to moderate on the last two sessions. In session 3, there was a high increase of screaming's frequency, as Eva's parents informed us, that Eva had bad sleep during the night, resulting in a difficult morning transition. Therefore, overall, these data show a stable level of the behavior (Figure 4). 


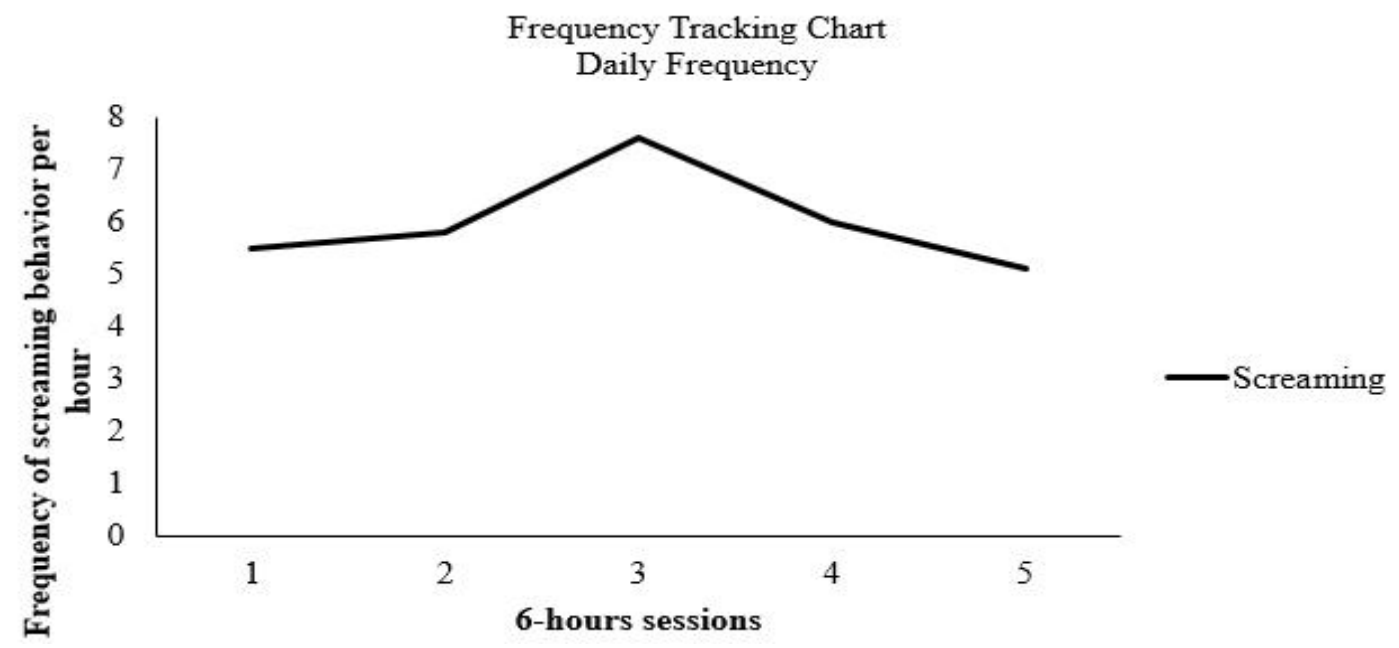

Figure 4. Frequency of screaming behavior across five 6-hours sessions.

\section{Duration}

As shown in Figure 5, the baseline duration of screaming reflected the trend observed in the frequency data.

\section{Duration Tracking Chart \\ Daily Duration}

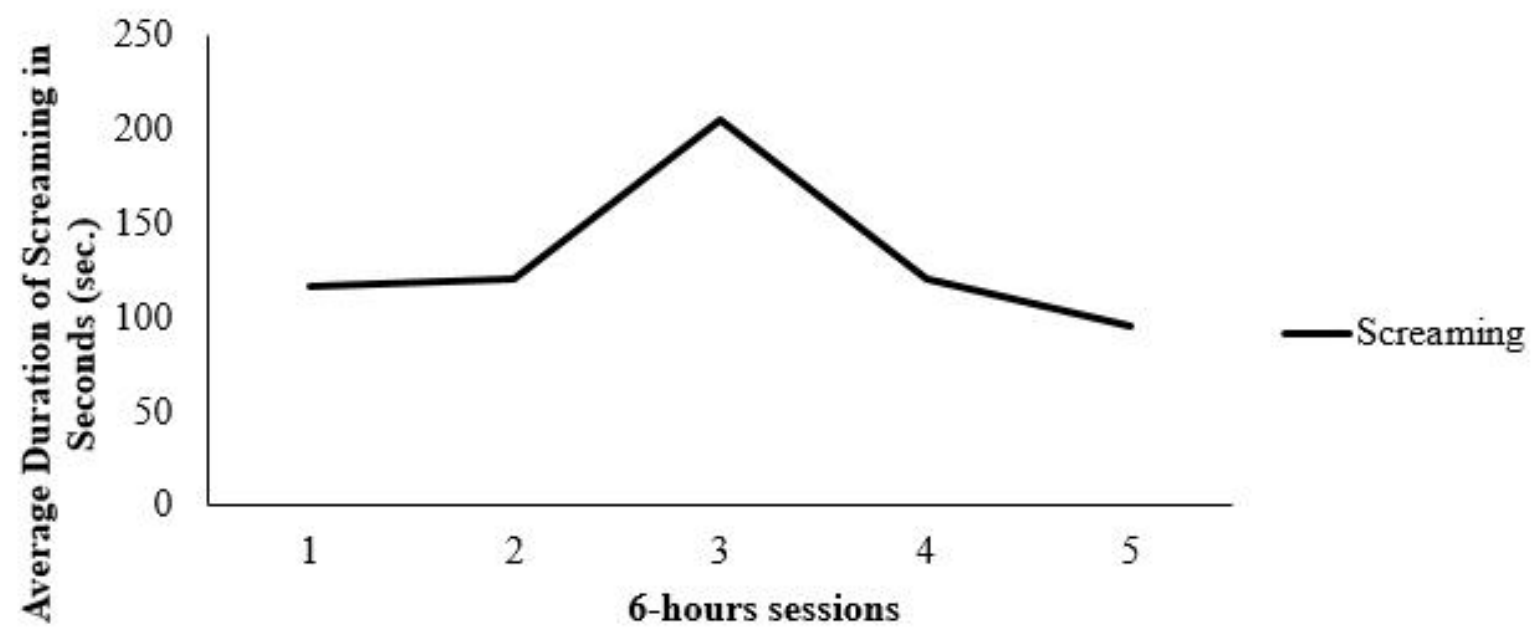

Figure 5. Assessment of screaming by Eva depicted as average duration in seconds within five 6 hours' sessions.

\section{Interobserver Agreement (IOA)}

For all the observations, there was a exact agreement between the two observers, with mean IOA of $100 \%$. This IOA agreement shows the integrity in the implementation of all the assessment procedures from the therapist (Figures 6-9). 


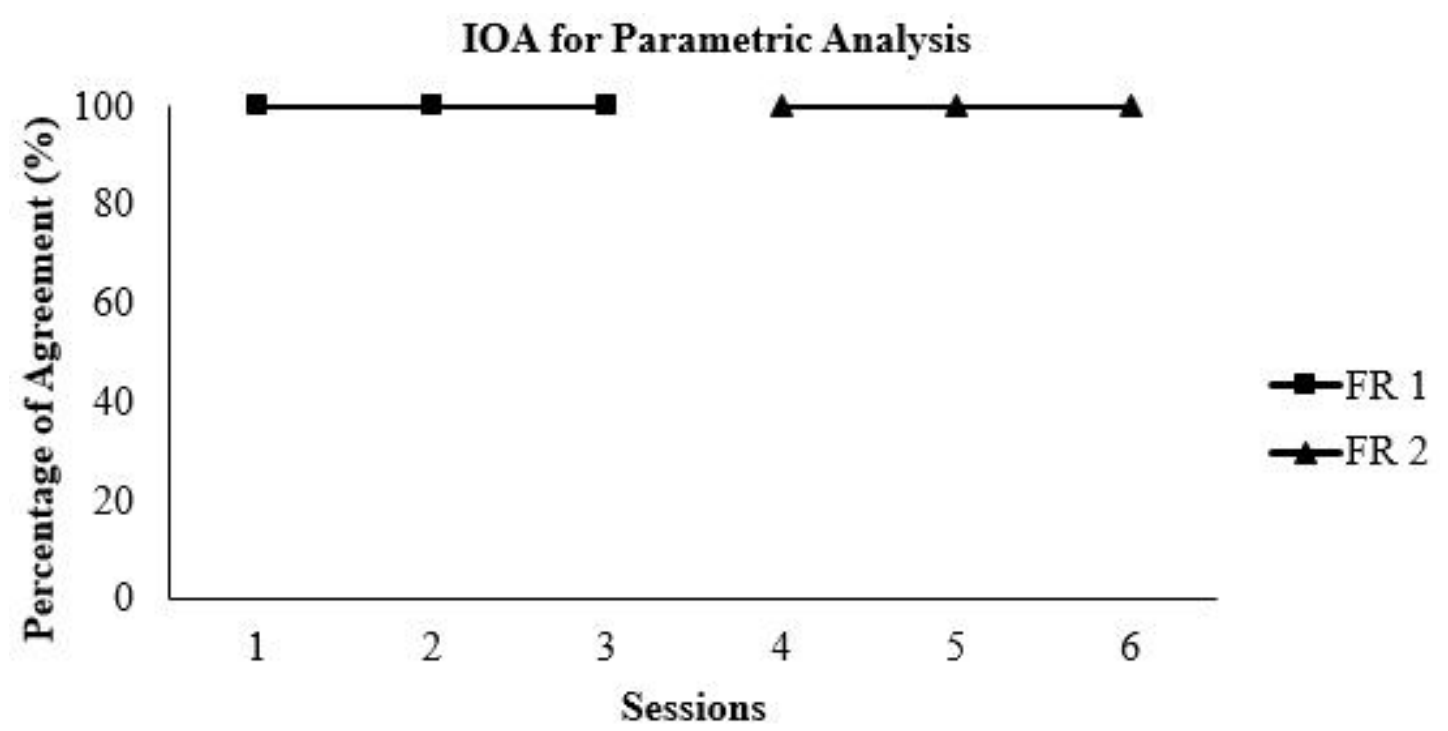

Figure 6. Mean IOA of parametric analog assessment, across two therapist-observers within 6 sessions.

IOA for A-B-C

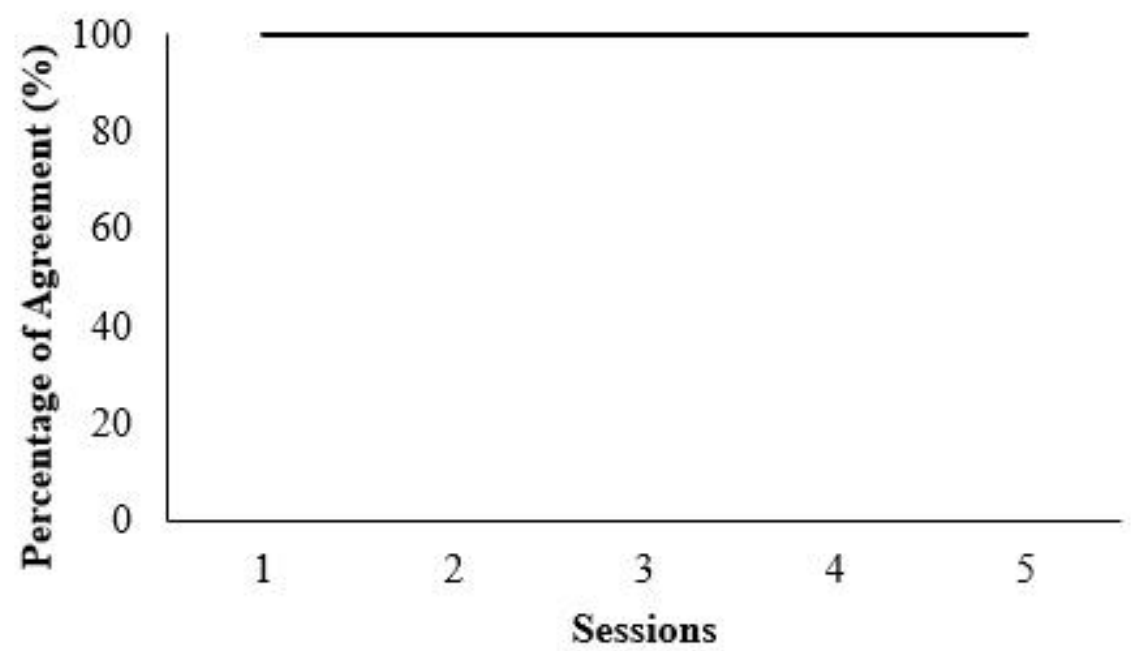

-Mean IOA

Figure 7. Mean IOA of antecedent-behavior-consequence (A-B-C) assessment, across two therapistobservers within 5 sessions. 


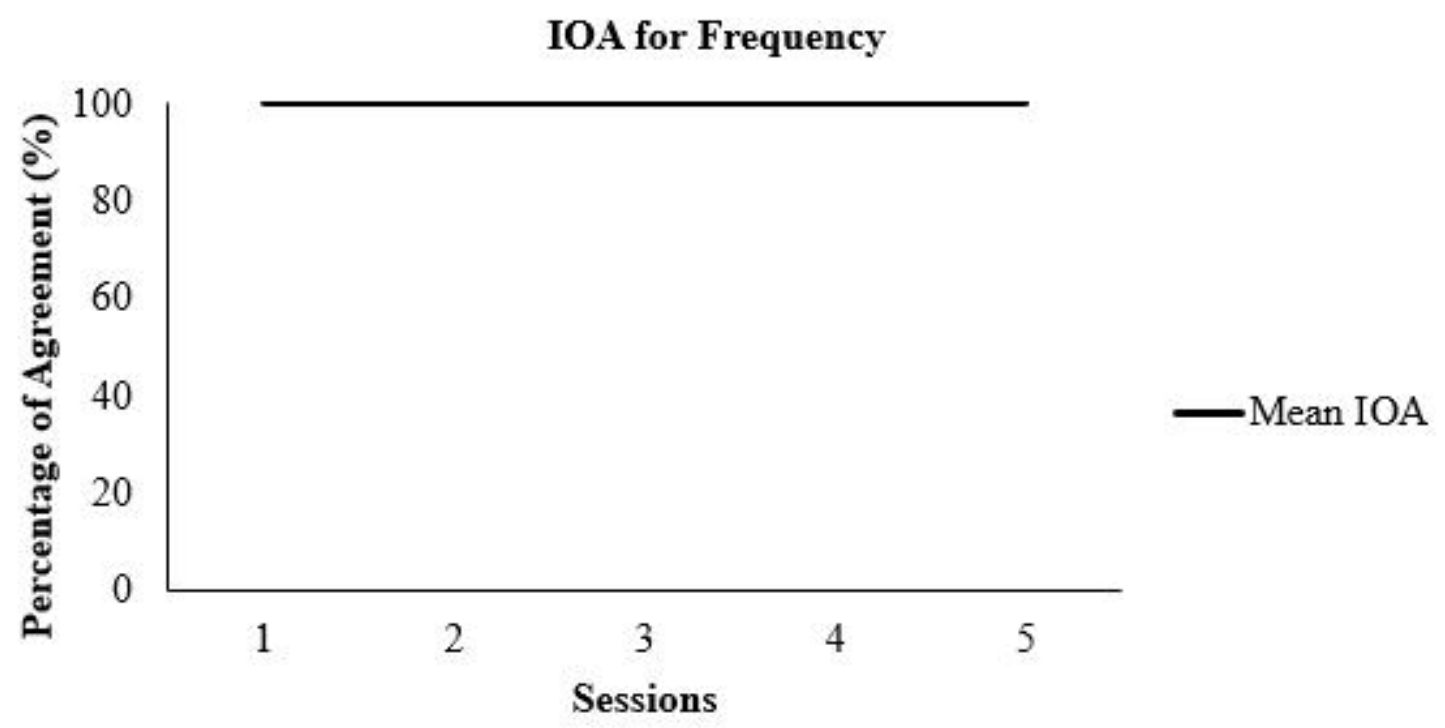

Figure 8. Mean IOA of frequency (of screaming behavior), across two therapist-observers within 5 sessions.

IOA for Duration

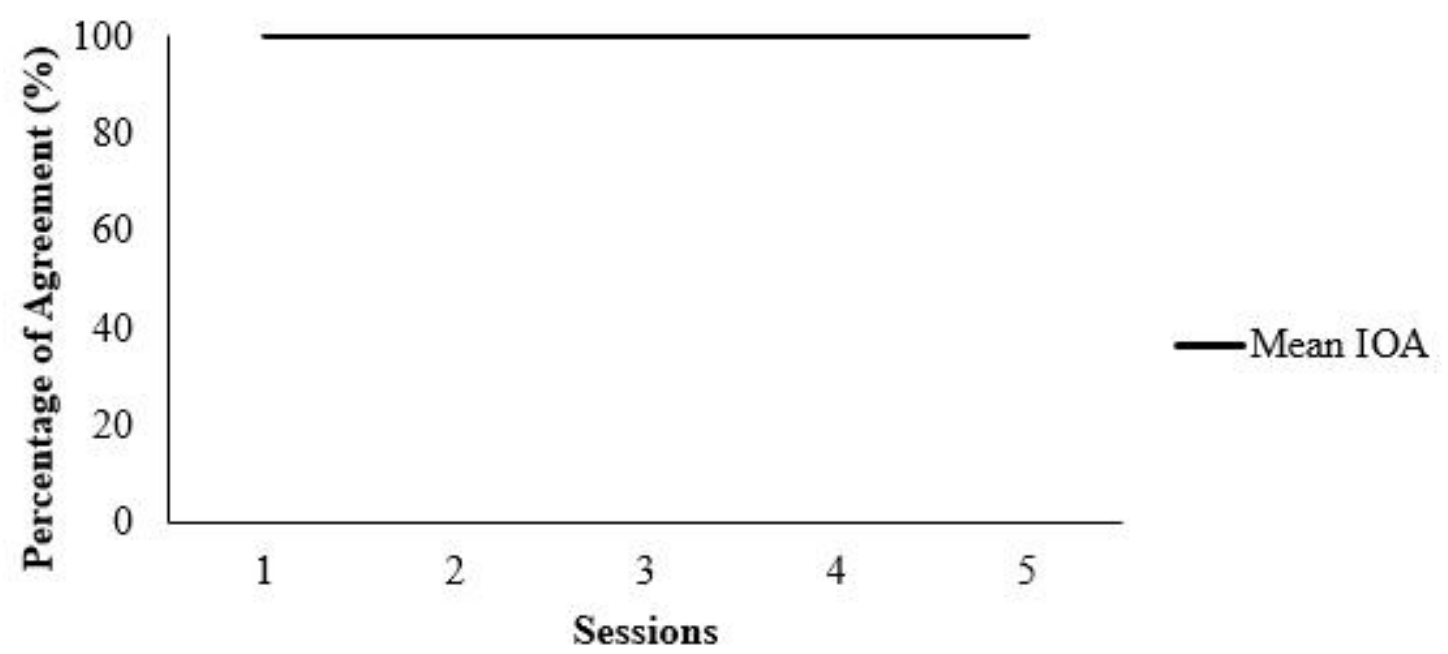

Figure 9. Mean IOA of duration (of screaming behavior), across two therapist-observers within 5 sessions.

\section{Functional Hypothesis of the behavior}

Based on the assessments, Eva engages in screaming, followed by flopping, crying, and headbanging, when this behaviour results in her gaining an item. Functionally, the behaviour is maintained by social positive reinforcement in the form of access to tangibles.

\section{Intervention Rationale}

Once we finalized our assessment plan, we proposed our intervention plan. Based on the assessment data that we collected, we identified that the most effective plan for Eva would be 
to introduce FCT program with manding for items and conducting preference assessment daily, at the beginning of every session. Based on the parametric analysis data, we identified that the most effective schedule of reinforcement would be the FR1, as Eva is more likely to engage in appropriately requesting for items and she is less likely to engage in screaming behavior.

Manding program will improve Eva's requesting skills and with the daily preference assessment we will know the items that she is motivated that day and we can use them as target skills. Moreover, by implementing FR1 during our intervention plan, we will enhance Eva's correct and appropriate requests for items and will reduce the occurrences of screaming.

\section{Intervention Plan}

\section{FCT/Mand training}

Based on the assessment data, the function of Eva's screaming behavior, which was access to tangibles, would be replaced by a more appropriate behavior. The replacement behavior would be requesting for items when they are present, using whole words or appropriate verbal approximations.

That skill was taught in the natural environment. The therapist had to make sure that there was an MO for the item. The mediator could gain Eva's motivation by letting her briefly engage with it, removing the item with a countdown, and, as she showed motivation, prompting her to request for it using a most-to-least hierarchy. For the first step, if Eva emitted an incorrect response or did not respond within $3 \mathrm{~s}$, the therapist provided a full verbal prompt. If she manded correctly with the prompt, the therapist provided the item immediately.

For the second step, the therapist re-contrived the motivating operation and provided a partial verbal prompt. The last step required independent performance. After every correct response (FR1), the therapist reinforced Eva's request by giving her the item and verbal praise. Once Eva had mastered this step, the therapist would help her to generalize that skill, across novel locations, people, and stimuli. The final step will be to maintain that skill and work on that weekly, bi-weekly, and finally monthly. To move to the next prompting level or generalization step, Eva had to achieve $100 \%$ for 2 consecutive days or $80 \%$ for 3 consecutive days, across two therapists. Across all the sessions, the therapist collected and graphed data on the daily percentage of correct mands. 


\section{Preference Assessment}

A paired-choice preference assessment was conducted prior to Eva's sessions. The therapist selected eight items that she had observed Eva interacting with the most and wrote them on the data sheet. Then she placed the items, one pair at a time, in front of Eva, and told her to pick one. As soon as she chose an item, the therapist quickly removed the other item. This process was repeated for the entire set of items, with each item presented twice overall, on the left and on the right. The preference assessment took place across 10 consecutive sessions.

\section{Results of preference assessment}

We identified that the most preferred items for Eva were the IPAD, ponies, princesses, and dolls. We also found that the least preferred items were plastic eggs, minions, Elmo, and the bird toy. Across the 10 days of preference assessment implementation, there were no changes in relative item preference. Results for the first session of preference assessment implementation are shown in Figure 10.

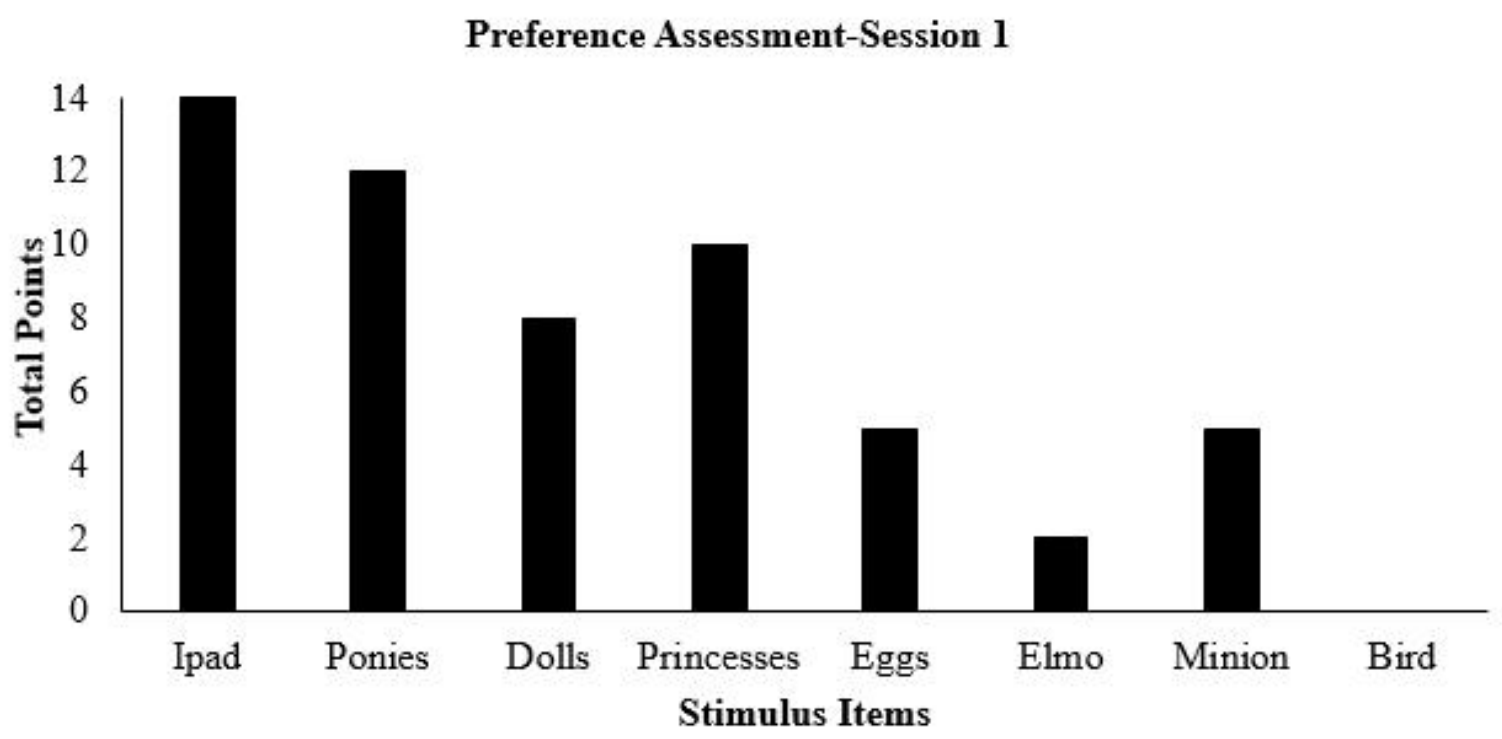

Figure 10. Paired-choice stimulus preference assessment across eight preferred items during the first session.

\section{Interobserver Agreement (IOA)}

The IOA was implemented during the intervention, across 3 consecutive sessions. The two therapist- observers recorded the performance of the therapist the time she implemented the intervention strategies. The total count of IOA was calculated by dividing the smaller count by the larger count and multiplying by 100 (Cooper et al., 2007, pp.102-124). 


\section{Clinical Report}

The therapist received an Individual Program Plan (IPP), a clinical report for Eva, which would assist her to build Eva's capabilities. The IPP provided a description of the client and her target behavior, the prescribed assessment outcomes, the intervention that took place, outcomes to date, and next steps that should be followed.

\section{Results}

\section{Mand Program}

Figure 11 shows the percentage of correct mand responses across 10 consecutive days. Throughout the intervention, she acquired the mand at a steady rate, ending at a mastery level.

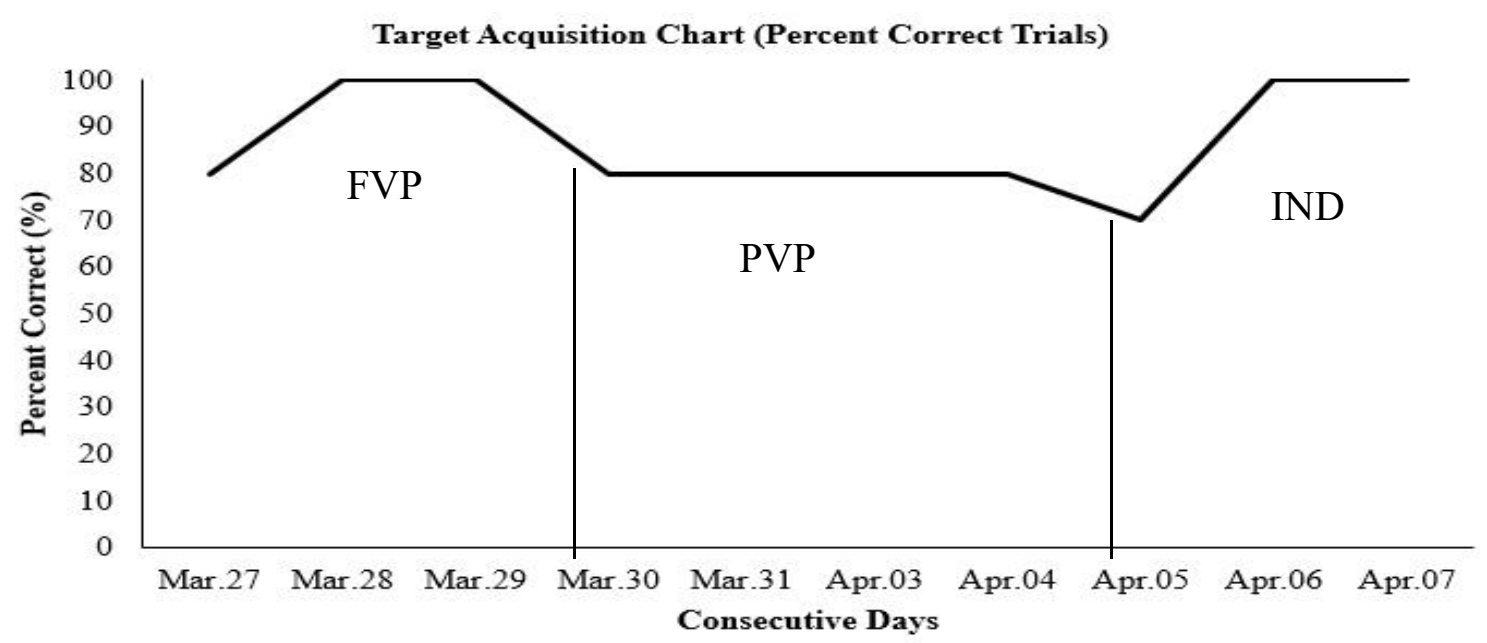

Figure 11. Percentage of correct mands (vocal request for items: ponies) across 10 consecutive days, during full verbal prompting (FVP), partial verbal prompting (PVP), and independent performance (IND).

Comparing the baseline and the intervention frequency data of screaming, once Eva started the manding program, the occurrence of her target behavior dramatically decrease. More specifically, during the baseline, Eva used to engage in screaming maximum almost 8 times per hour and minimum 5 times per hour. During the intervention, she engaged in screaming maximum 4,5 times and minimum 1,6 times per hour. By analyzing both mand and frequency of screaming data, we can state that our intervention plan was effective for Eva, as we improve her requesting and we also reduce the occurrence of screaming every time she wanted to ask for items (Figure $12-13$ ). 


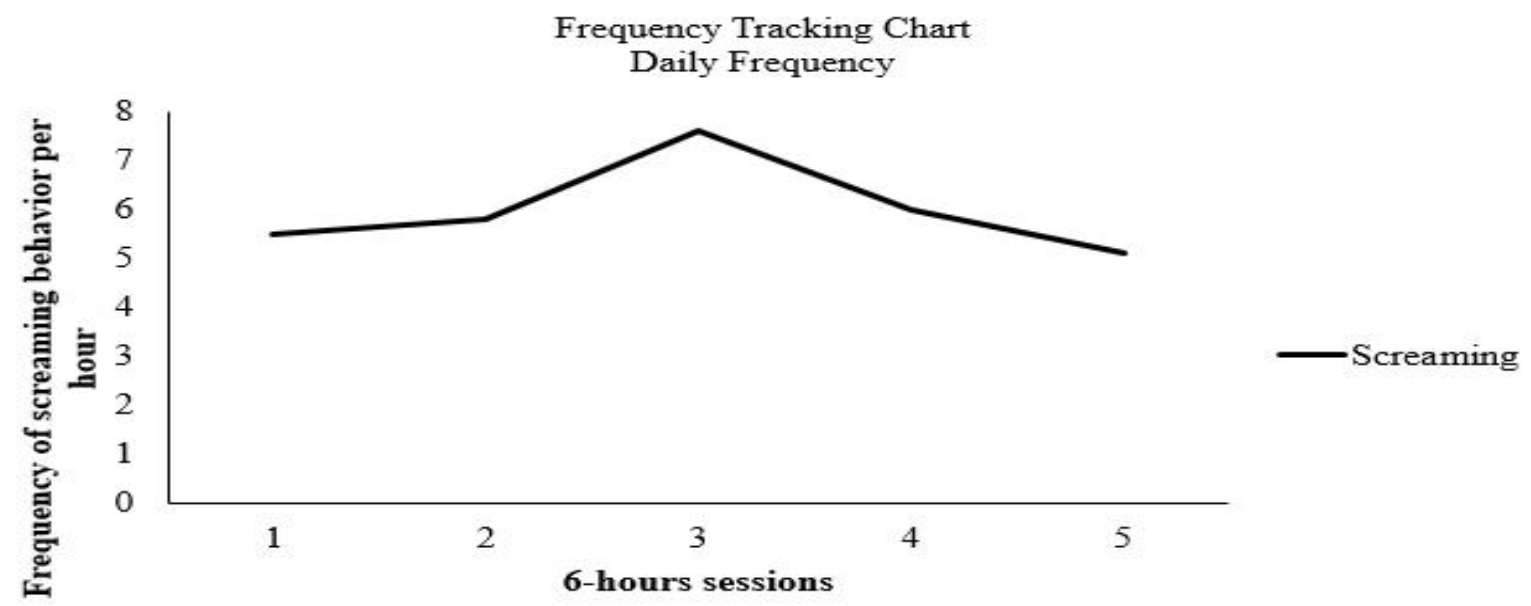

Figure 12. Frequency of screaming behavior across five 6-hours sessions (Baseline Data)

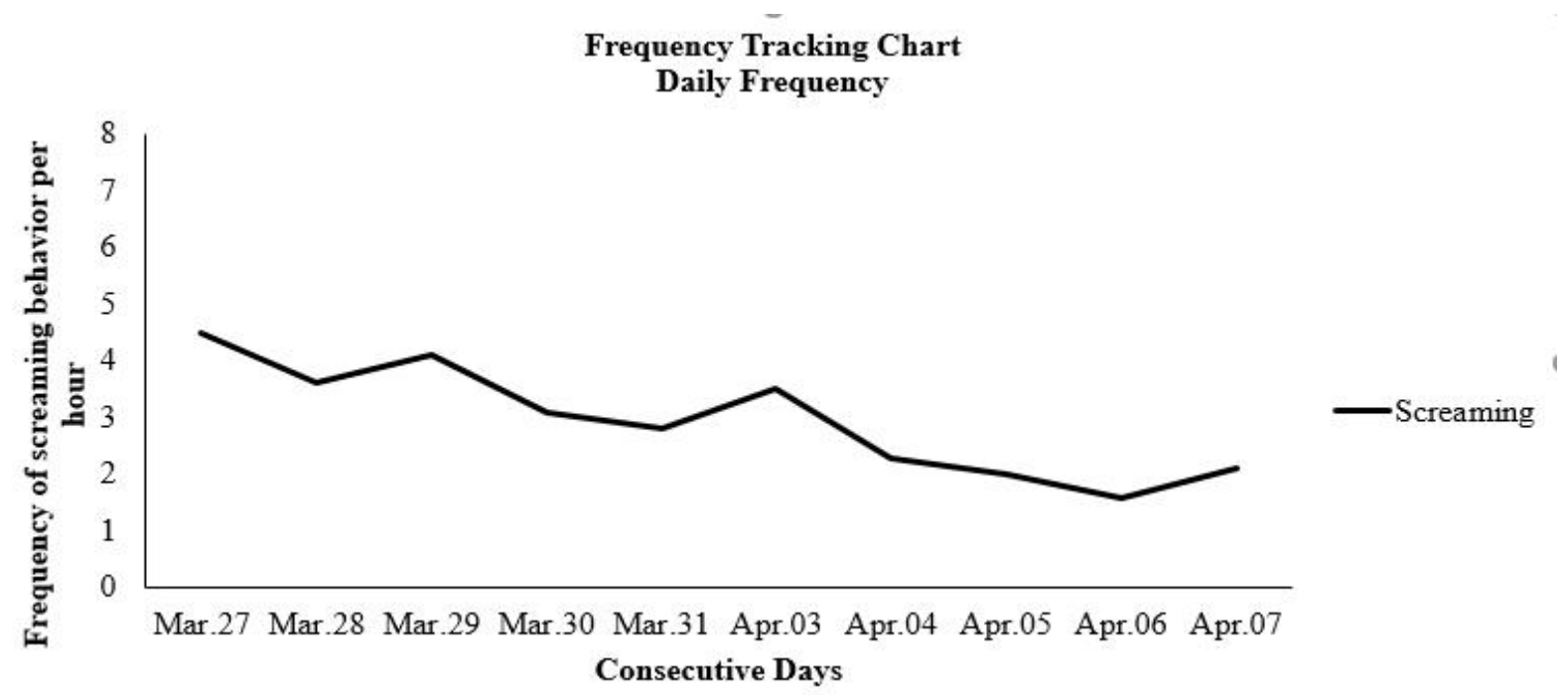

Figure 13. Frequency of screaming behavior across 10 6-hours sessions (Intervention Data).

\section{Interobserver Agreement (IOA)}

IOA was conducted during the preference assessment, mand training, and frequency recording preference assessment program and the recording of frequency data. For all the observations, there was an exact agreement between the two observers/ITs with mean IOA of $100 \%$ (Figures 14-16). 


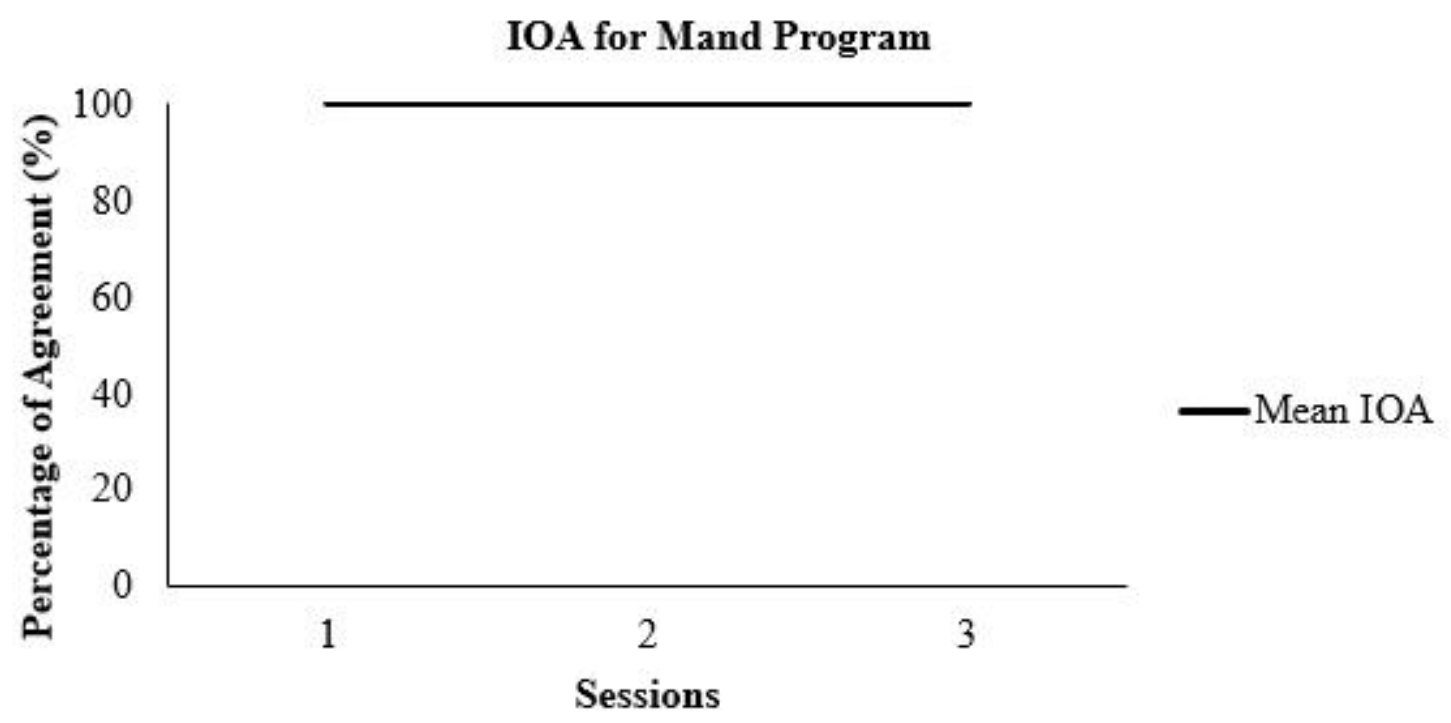

Figure 14. Mean IOA of mand intervention, across two therapist-observers within 3 sessions.

\section{IOA for Preference Assessment}

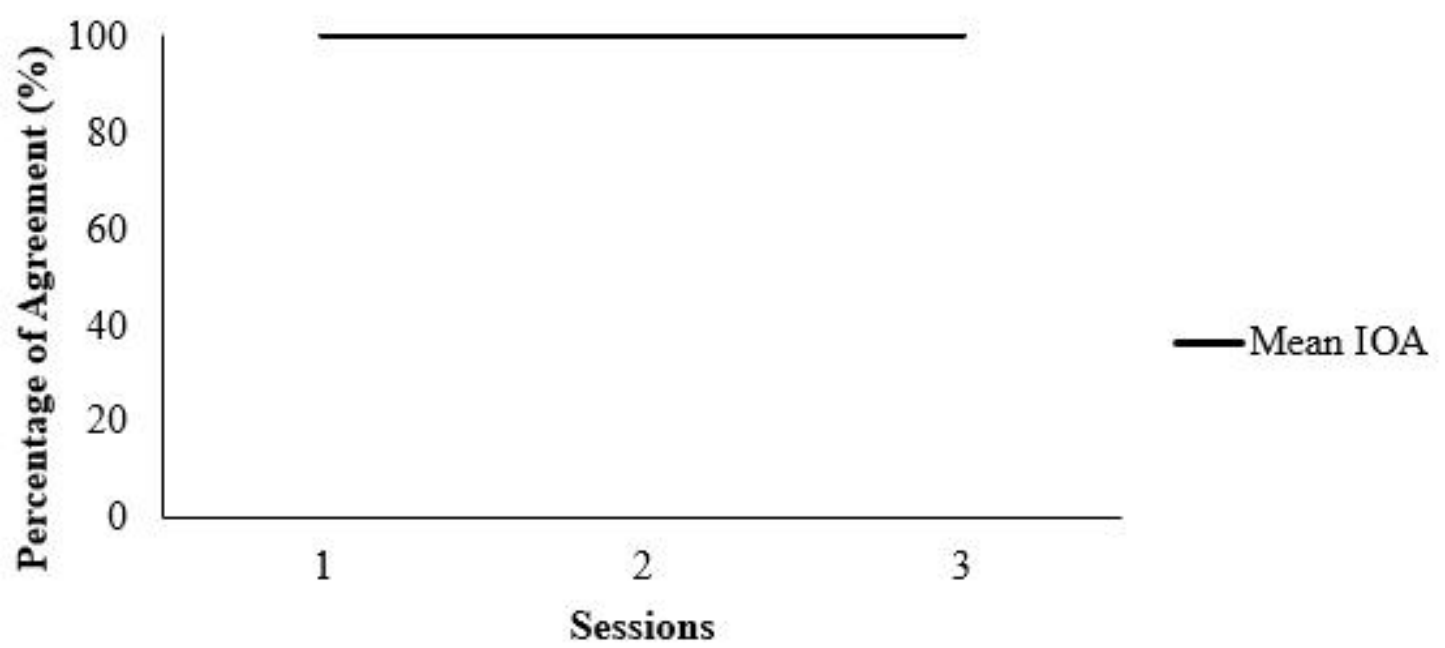

Figure 15. Mean IOA of paired-choice preference assessment, across two IT-observers within 3 sessions. 


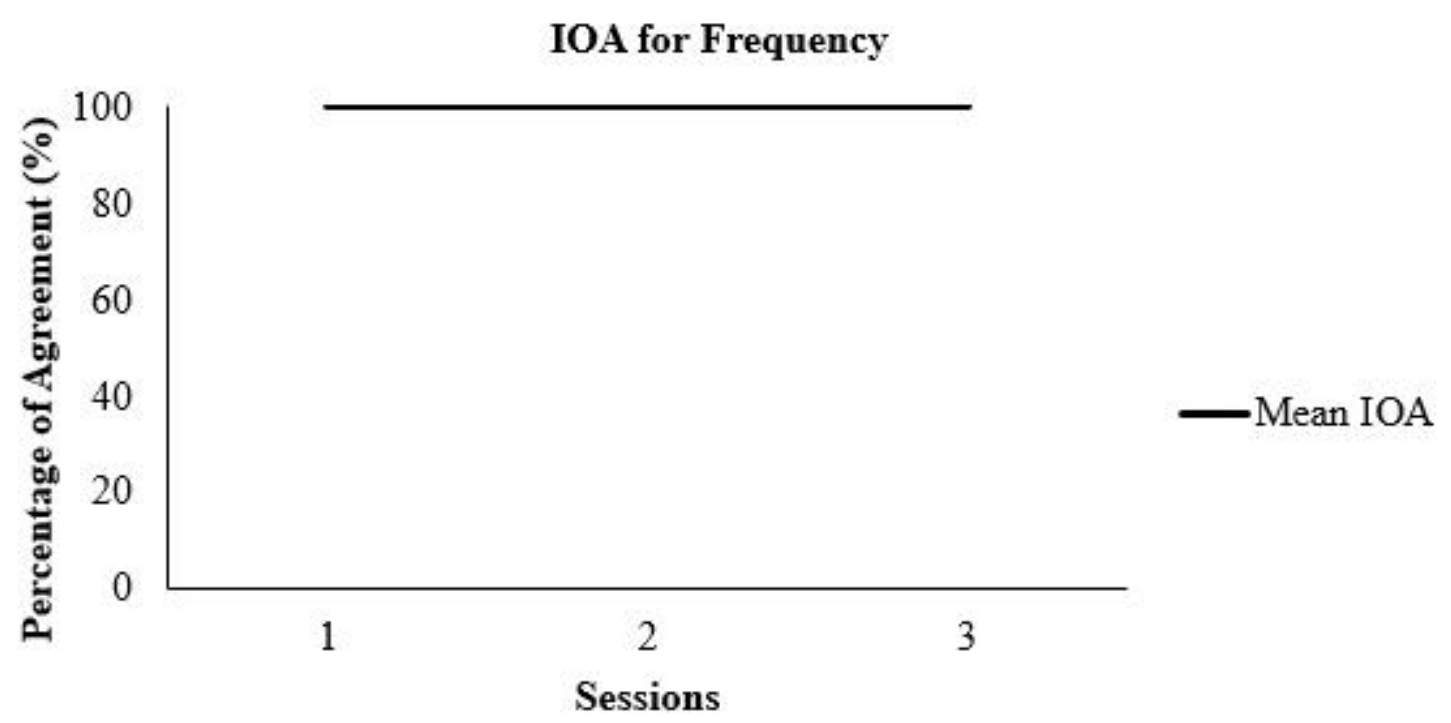

Figure 16. Mean IOA of frequency measurement, across two therapist-observers within 3 sessions.

\section{Discussion}

The assessment results suggest that screaming was maintained by access to tangibles. More specifically, the data showed that, when Eva's verbal repertoire was lacking, she was very likely to engage in screaming to access a preferred item. Baseline data showed that she often engaged in screaming, which reliably preceded flopping, head-banging, and crying, during her 6-hr sessions. Conducting daily preference assessments and mand training sessions effectively maintained low rates of screaming and high rates of appropriate requests for preferred items.

Although the project generally worked well, it had a few limitations. More specifically, during our measurement procedure, it would have been helpful to video-tape our sessions to facilitate the recording of the frequency and the duration of Eva's screaming. Videotaping would help to avoid mistakes in data collection in real-time. Haidet, Tate, Divirgilio-Thomas, Kolanowski, and Happ (2009) suggested that video recordings allow for more reliable data collection because they can be re-played many times and provide high degree of reproducibility.

The final limitation relates to the amount of materials the therapist had to carry for the purposes of this intervention, which included data sheets, a timer, and tally counters. At the same time, she had to observe Eva and record instances of her screaming. We found that the therapist occasionally had difficulty managing these aspects, especially when Eva had to be transitioned to another space where she still had to record data. 
To mitigate the limitations outlined above, we could have initially better organized our assessments and identify a more efficient but effective way to record frequency and duration data. For instance, we could have considered collecting scatterplot data to determine if there are certain times of the day that screaming occurs more frequently. We could have also spent more time conducting the literature review on assessment to identify the effectiveness of video-taping and then could have attempted to implement it in our project.

\section{Conclusion}

At the end of this study, we identified that we should be careful about what we want to assess, why need to assess it, and how we will do that, considering the most relevant research articles. During every single step, starting from the assessment, and finishing to the treatment plan, as Behavior Therapists, we should pay attention and try to spend as much time as possible reviewing the literature and providing mediator training until we make sure that the therapists will implement our plan accurately.

Across the project, we should also frequently observe our trainees and how our plan goes, to ensure our clients' progress, and our trainees' satisfactions. Every client deserves the best services and it is our responsibility to ensure that we continue providing that at every step.

\section{References}

[1] Bailey, J. S., \& Burch, M. R. (2016). Assessing Behavior (Code 3.0). In Bailey, J. S., \& Burch, M. R. (Eds.), Ethics for behavior analysts: $3^{\text {rd }}$ Edition (pp. 109-122). New York, NY: Routelge.

[2] Bailey, J. S., \& Burch, M. R. (2016). Behavior analysts and the behavior-change program (Code 4.0). In Bailey, J. S., \& Burch, M. R. (Eds.), Ethics for behavior analysts: $3^{\text {rd }}$ Edition (pp. 123-140). New York, NY: Routelge.

[3] Bijou, S. W., Peterson, R. F., \& Ault, M. H. (1968). A method to integrate descriptive and experimental field studies at the level of data and empirical concepts. Journal of Applied Behavior Analysis, 1, 175-191.

[4] Canella, H. I., O’Reilly, M. F., Lancioni, G. E. (2005). Choice and preference assessment research with people severe to profound developmental disabilities: a review of the 
literature. Research in Developmental Disabilities, 26(1), 1-15. Doi: 10.1016/j.ridd.2004.01.006

[5] Chiang, H. M. (2008). Expressive communication of children with autism: The use of challenging behaviour. Journal of Intellectual Disability Research, 52(11), 966-972. Doi: 10.1007/s10803-007-0423-Z

[6] Cooper, J. O., Heron, T. E., \& Heward, W. L. (2007). Selecting and Defining Target Behaviors. In Cooper, J. O., Heron, T. E., \& Heward, W. L. (Eds.), Applied Behavior Analysis- Second Edition (pp. 48-71). Upper Saddle River, NJ: Pearson Education Inc.

[7] Cooper, J. O., Heron, T. E., \& Heward, W. L. (2007). Improving and assessing the quality of behavioral measurement. In Cooper, J. O., Heron, T. E., \& Heward, W. L. (Eds.), Applied Behavior Analysis - Second Edition (pp. 102-124). Upper Saddle River, NJ: Pearson Education Inc.

[8] Galiatsatos, G. T., \& Graff, R. B. (2003). Combining descriptive and functional analyses to assess and treat screaming. Behavioral Interventions, 18(2), 123-138. Doi: 10.1002/bin.133

[9] Haidet, K. K., Tate, J., Divirgilio-Thomas, D., Kolanowski, A., \& Happ, M. B. (2009). Methods to improve reliability of video recorded behavioral data. Research in Nursing \& Health, 32(4), 465-474. Doi: 10.1002/nur.20334

[10] Johnson, C. P., \& Myers, S. M. (2007). Identification and evaluation of children with autism spectrum disorders. Pediatrics, 120(5), 1183-1215. Doi: 10.1542/peds.2007-2361

[11] Kahng, S., Ingvarsson, E. T., Quigg, A. M., Seckinger, K. E., \& Teichman, H. M. (2011). Defining and Measuring Behavior. In Fisher, W. W., Piazza, C. C., \& Roane, H. S. (Eds.), Handbook of Applied Behavior Analysis (pp. 113-131). New York, NY: The Guilford Press

[12] Koegel, L. K., Koegel, R. L., Boettcher, M. A., Harrower, J., \& Openden, D. (2006). Combining functional assessment and self-management procedures to rapidly reduce disruptive behaviors. In Koegel, R. L., \& Koegel, L. K. (Eds.), Pivotal Response Treatments for Autism (pp. 245-258). Baltimore, Maryland: Paul H. Brooks Publishing Co., Inc.

[13] Matson, J. L., Kozlowski, A. M., Worley, J. A., Shoemaker, M. E., Sipes, M., \& Horovitz, M. (2011). What is the evidence for environmental causes of challenging behaviors in persons with intellectual disabilities and autism spectrum disorders? . Research in Developmental Disabilities, 32(2), 693-698. 
[14] Matson, J. L., \& Vollmer, T. (1995). Questions about behavioral function (QABF). Baton Rouge, LA: Disability Consultants, LLC.

[15] McClintock, K., Hall, S., \& Oliver, C. (2003). Risk markers associated with challenging behaviors in people with intellectual disabilities: a meta-analytic study. Journal of Intellectual Disability Research, 47(6), 405-416.

[16] O’Neil, R. E (1990). Establishing verbal repertoire: Toward the application of general case analysis and programming. The Analysis of Verbal Behavior, 8, 113-126.

[17] Paired choice preference assessment datasheet. (n.d.). In behavioral -solutions.com. Retrieved from http://behavioralsolutions.com/Portals/0/Lethbridge $\% 20$ Forms/Reinforcement\%20Preference $\% 20$ Assessment-\%202.pdf

[18] Piazza, C. C., Fisher, W. W., Hagopian, L. P., Bowman, L. G., \& Toole, L. (1996). Using a choice assessment to predict reinforcer effectiveness. Journal of Applied Behavior Analysis, 29, 1-9.

[19] Reed, D. D., \& Azulay, R. L. (2011). A Microsoft Excel ${ }^{\circledR}$ based tool for calculating interobserver agreement. Behavior Analysis in Practice, 4(2), 45-52.

[20] Rutherford, C. (2012). Critical Review: Effectiveness of functional communication training using augmentative and alternative communication on the challenging behaviour of children with autism. Retrieved from https://www.uwo.ca/fhs/csd/ebp/reviews/201112/Rutherford.pdf

[21] Sigafoos, J., \& Meikle, B. (1996). Functional communication training for the treatment of multiple determined challenging behavior in two boys with autism. Behavior Modification, 20(1), 60-84. Doi: 10.1177/01454455960201003

[22] Sundberg, M. L. (2008). VB-MAPP: Verbal behavior milestones assessment and placement program. Concord: AVB Press.

[23] Tarbox, J., Wilke, A. E., Najdowski, A. C., Findel-Pyles, R. S., Balasanyan, S., Caveney, A. C., Chilingaryan, V., King, D., M., Niehoff, S. M., Slease, K., \& Tia, B. (2009). Comparing Indirect, Descriptive, and Experimental Functional Assessments of Challenging Behavior in Children with Autism. Journal of Developmental and Physical Disabilities, 21(6), 493-514. Doi: 10.1007/s10882-009-9154-8

[24] Watkins, M. W., \& Pacheco, M. (2000). Interobserver agreement in behavioral research: Importance and calculation. Journal of Behavioral Education, 10(4), 205-212. Doi: 10.1023/A:1012295615144 